\title{
Event Measuring of Childhood
}

\section{Diana I. Mamycheva}

\author{
Vladivostok state university of economy and service, 690014, Gogolya 41, Vladivostok, Russia
}

\section{Doi:10.5901/mjss.2015.v6n6s3p240}

\section{Abstract}

As the subject matter the paper considers a psychoanalytic concept of the subject as that which life is not some natural selfreality but formation and self-creation, incompleteness appears. An opportunity of articulation, speech as own, full speech is becoming a criterion of the construction of subjectivity. To be the author of own life, a person must find, build own story. This opportunity, in turn, is connected with the fact of "the event" as actualization of sensual-corporal and reflexive, meaning, injuring thing. An idea of the defining impact of childhood on the whole subsequent life of the subject makes it the subject of special interest, clarification of a character of this influence. The actual validity of childhood which everyone has and nobody can pass owing to age milestones change makes childhood something clear and obvious. Psychoanalytic conceptualization of the subject has found the key complexity and heterochrony of remembrances and the vital fact. An individual is always connected by his childhood not because this dictate is predetermined by its chronological precedence (from the point of view of classical determinism) to the other stages, and in view of habitation of other spaces of the outside world and expansion of the inner world which movements are described by the special logic of deepening, rediscovering and determining the senses of childhood episodes in a new way or anew. Childhood as the event of personal story is understood as the value, sense made by the whole set of sincere experience, but not as autonomous, substantive, invariable, once stated state or event.

Keywords: remembrance, memory, narrative, aftereffect, childhood.

\section{Introduction}

For today one of the key concepts of philosophy is the concept "event". Actualization of this concept is connected with such philosophical directions as E. Husseri's phenomenology, M. Heidegger's fundamental ontology, S. Freud's psychoanalysis. These fundamental projects in a new way comprehending the bases of subjectivity of a European person pay much attention to the questions of ontology, the nature of life of the subject, and those bases which make this life evident. The way which these philosophical projects have paved causes such reference points as daily occurrence, life with - others, communicativeness, personal story creating a new basis for the systems of attitudes and thought. Having designated the fundamental directions of thought which have influenced subjectivity of a modern person, the subject matter of our concentration will be a psychoanalytic discursive thing in childhood thematization (Figdor, G., 2008). The connection between a psychoanalysis and childhood - connections are not casual, but intrinsic. Having concentrated its attention on personal story, the psychoanalytic optics became the basis for completely another conceptualization of childhood having created other having created a theoretical and practical alternative to pedagogical, psychological, medical knowledge (Epstein, M.N., 2003). But along with another conceptualization of the mental development of a child, a psychoanalysis articulated the way how childhood "works" in the adult subject. Perhaps, one of the most widespread theses correlated to a psychoanalysis is an idea of the defining influence of childhood on the subsequent human life. It seems that a character of this influence is not axiomatic and demands clarification. The hypothesis is that childhood in personal story is not some reality, it is something necessary to appropriate, actualize, something that has a character of the dynamic, but not static beginning.

Complication of the internal reality of a modern person who has found a difficult character of the language, image, action inevitably turns into the search of the steady bases which finding is carried out by means of the individual story forming. And in this story childhood is one of the fundamental questions, an effort of its comprehension becomes interfaced to the existential event, the need for finding out the individual project of childhood that, in fact, realizes the ability to be the subject. 


\section{Literature Review}

Among the native works M.M. Bakhtin's, A.A. Gryakalov's, V.B. Melas's researches consider the event analytics. A.A. Gryakalov thinks that "the event" as a place of "assembly" symbolical and subject things, as "assembly" of the subject at the time of the sense forming when at the same time sensual-corporal and reflexive things are actualized (Gryakalov, 2004). The researcher's analytics concentrates on the esthetic event, but it seems that the event thematization as actualization of sensual and reflexive things can be widespread out of the limits just of the esthetic experience (Ovchinnikov, A.I., Mamychev, A.Y. \& Mamycheva, D.I. 2015).

The issue of subjectivity formation conditions is a thread psychoanalytic theory and practice. It can note some directions: the French analytical tradition presented by Zh. Lakan and F. Dolto. As an important condition of subjectivity formation Zh. Lakan and F.Dolto consider an injury, a ban and the Other as somebody who establishes a ban (Dolto, 1985). The English line is presented by names D. Vinnikott and M. Klein. Vinnikott says about such ways of life accommodation as disease, adaptation and creativity. Adaptation demands the accommodation to the environment, illness demands the dependence on creativity of the other one, creativity demands being pleased by life. These patterns in Vinnikott's concept are connected with children's separation experience and the ability to separate from each other I and the other, the external and internal reality (Winnicott, 1971).

Among S. Freud's works it is possible to distinguish some directions of childhood research:1) reconstruction of adults' remembrances of childhood (a genetic approach) (the works "Children's remembrance of Leonardo da Vinci" (1910), "Children's remembrance of Goethe from "Poetry and Truth" (1917), "From the story of one children's neurosis" (1918); 2) the direct research of behavior of a child (the works "Sexuality in hypnosis etiology " (1898), "Three sketches on the theory of sexuality" (1905), "On the theory of infantile sexuality" (1908), "An analysis of phobias of a five-year-old boy" (1909), "From the life of children's soul", "A child is beat" (1921), "The introduction to psychoanalysis" (1916).

\section{Methods and Materials}

The methodological basis of the paper is the analytical reconstruction in combination with hermeneutical methods (Foucault, M. , 2010). The research have also used epistemological methods of the humanitarian knowledge reconstruction psychoanalytic interpretation as a method of deep hermeneutics, deconstructional methods.

The theoretical source is a number of S. Freud's works. The issue of children's remembrances is repeatedly brought up by Freud in a number of his works: "On the covering remembrances" (1899), "On childhood remembrances and remembrances serving as the cover" (1901), "Remembrances, reproduction and processing" (1914) in the "Lectures on introduction to a psychoanalysis" (1916/17), and it was originally connected with an aspiration to establish reliability of the narration, to reconstruct a background of the vital events as conditions of understanding of the actual circumstances of the individual formation, to find some localized prime cause and its dynamic role in the mental life structuring. The unambiguous solution of this issue has faced a number of difficulties which permission made one of the conceptual provisions of a psychoanalysis which in many respects was the basis of reconsideration of the classical concept of the subject as the sovereign, complete, equal to you individual.

\section{Results and Discussions}

It should be noted that childhood has some temporary correlation. One of the characteristic definitions of childhood emphasizes the reference to the concrete age period, its beginning and end. Depending on the subject area (psychology, jurisprudence) childhood is the life period from the birth and till 13-15 years. This definiteness of childhood assumes it as some obvious reliability certified by everybody. Childhood is something that has everyone in some existence as the fact.

Of course, our remembrances of childhood is an important condition of our experience which make the most direct, as a rule, bright, given us in emotional intensity, evidence able to start from. This evidence, that the nearest field proceeding from which own knowledge what childhood is (I was there), who is a child (I was him), which is the cornerstone of the daily experience can be made. The unsophisticated look does not call in question continuity and reliability of this knowledge carrying out a direct link between the remembrance and the vital fact, remembrance as a print of a series of real events.

The critical movement of judgment of the ontological register of childhood remembrances, a character of their reliability, features of a narrative form, that counterpoint where a psychoanalysis and philosophy meet and which is inevitably setting the extensive perspective of time, memory broader than the questions of the subject institutionalization.

The problematic field of a psychoanalytic thematization of childhood was formed in social practice. Chronological 
and methodical precedence concerned the adult's figure. The adult acted as that who initiated the psychoanalytic relations, articulated the inquiry. In the analysis space the adult was the closest subject of interest, that who formulated the questions and was the question for an analysis. Childhood arose in the field of the analytical review as that what experienced the remembrance, a subject of alarms, revelations or concealment, but thus as something permanently effective saturated. Its retrospective emergence on the analytical scene has defined a circle of the related values. Childhood was the narration, the narrative, the story of a particular person. And as the verbal embodiment was taking a sounding shape and a figurative embodiment. This narration about childhood proceeded from the adult subject and was intoned by the mental life of the adult consciousness. The question arising in connection with a field of these values concerned several moments: does the remembrance of childhood reproduce a concrete situation in the past being as if a picture of the last event? Is reliability of the real event as the substantial filling and the reason of remembrance called into question and then, what does fill and constitute so-called "the experience of childhood" of a particular person, what do we have as "children's remembrance"? What is an ontological register of "the remembrance of childhood", whether it is connected with the past, present or future? What does in general happen when we find some remembrances as "the experience" of our childhood? The reflection in this direction is connected with the assumption of essential complexity and opacity of the relations of a person with his own childhood.

The issue of children's remembrances is repeatedly brought up by Freud in a number of his works: "On the covering remembrances" (1899), "On childhood remembrances and remembrances serving as the cover" (1901), "Remembrances, reproduction and processing" (1914) in the "Lectures on introduction to a psychoanalysis" (1916/17), and it was originally connected with an aspiration to establish reliability of the narration, to reconstruct a background of the vital events as conditions of understanding of the actual circumstances of the individual formation, to find some localized prime cause and its dynamic role in the mental life structuring. The unambiguous solution of this issue has faced a number of difficulties which permission made one of the conceptual provisions of a psychoanalysis which in many respects was the basis of reconsideration of the classical concept of the subject as the sovereign, complete, equal to you individual.

In the work "On childhood remembrances and remembrances serving as the cover" Freud pays his attention to a contradiction between the visible insignificance of the remembrance contents of childhood and duration as a steady image of the last event. Possibility of understanding of this contradiction is connected by Freud with the reasons clarification of the remembrance activization. Is the feature of children's mentality such prerequisite and thus the reason goes to that early period when children's consciousness in a special way perceived happening distinguishing and being late on that perspectives of the adult look are already insignificant. Such a situation could be the basis for the consideration of "insignificant remembrances" which saved in a steady-state condition since the childhood era as live, direct material for the reconstruction of intensions which are characteristic to the early experience, and an opportunity to observe yourself in children's remembrances would be explained by biased egocentrism peculiar to a child.

However, Freud does not stop on such a possibility of the explanation and develops the other prospect of view to the childhood remembrance. The analytical consideration finds heterochrony of the remembrance weaved from various temporary layers of the mental life of the subject appearing in miscellaneous of ratios of obvious and hidden things: either earlier remembrances are "covering" and the arising image does not correspond to its internal contents connected with later events; or significant early children's impressions are hidden under remembrances belonging to chronologically later events which play the role as covering. Thereby, the remembrance appears not equal to itself. The mechanics of the remembrance is connected with some kind of breakage as Freud says "a defect": reproduces not that it must be reproduced, but something another" (Freud, 2011, p. 46). And this "defect" is connected with the intervention of the biased factor favoring to one remembrance and interfering another. "Tendentiousness" of remembrance deprives them of their status of a guarantor of some external reliability of the events and at the same time this tendentiousness is extremely informative because it indirectly allows finding the zones of biased interest, the internal motive or the conflict.

This course of reflections significantly complicates the possibility of understanding and qualification of a remembrance of childhood which certainly stops to correspond to the register of the past. One of S. Freud's hypotheses is that the children's remembrance testifies not so much to the remained rudimentary splinters of the children's experience as how many it characterizes the actual moment of life of the subject. S. Freud writes: "... early children's remembrances represent not a real trace of old impressions, but its latest processing which was influenced by various mental forces of later time" (Freud, 2011, p. 42).

Thereby memory of childhood is not equal to itself, it avoids a direct look, demands essential informative effort to be caught. The subject can never overtake its own childhood in its spontaneity, definiteness and at the same time it has biased interest to it. This difficulty of understanding testifies to a zone of high existential tension. . An individual is always connected by his childhood not because this dictate is predetermined by its chronological precedence (from the point of 
view of classical determinism) to the other stages, and in view of habitation of other spaces of the outside world and expansion of the inner world which movements are described by the special logic of deepening, rediscovering and determining the senses of childhood episodes in a new way or anew. In this sense, the image of childhood is multiple, it is another depending on a character of the current peripeteias of the subject. But its supervalue consists in order to close a circle on the outcome, to fit into the story and give it the beginning, childhood as the purpose and the present as a source. In the movie "Wings of Desire. Faraway, so close" a director Wim Wenders embodies this special status of childhood memory in the story of the subject in an episode of the hero request, a former driver of Conrad turned to an angel Kassiel: "A little that I remember. When you die, it is necessary to know after all how I was living. Tell me my story". Kassiel's story begins with the narration about Conrad's childhood.

A human being does not think itself and cannot be out of the language. As for to think of itself, than exactly in the act of the word the subject not only speaks about itself, but in the act of the word the consciousness of the subject is also formed. Therefore the story about own childhood becomes that necessary condition in which childhood is constituted. The way of telling, creation of tha story. The modern model of the personality is based on that the personality is shown and the subject is thought as already present here, and its actions are resulting of that who it is which it must if not to open before others then, at least to take for it responsibility and to recognize. Existence of the subject which is being as that is already put being that involves solipsism of the modern subjectivity with its consequences described in terms of narcissism, rivalry with another and general competition for self-realization which in turn puts the contract and the right in the center of the human relations. The psychoanalytic concept of the person if it also does not ignore this fundamental part of a human being, puts in the subjectivity heart other determinism, determinancy of the person by the word which partially escapes somebody who speaks. So, the subject when it is the subject of that what it says, is also thought as the subject escaping summation as the subject who is shown by the alternation of gaps and interstices of presented information. Thus, determination of the subject in a psychoanalysis instead of creating the individual who is already being which must say in order to recognize what it is, assumes the subject in formation, the subject which as much as possible comes nearer to the essence while presented information escapes it. The truth function of the reservation or the symptom, that the individual produces on his own ignorance, consists in stating, at least partially, the truth about the subject; they (the reservation and the symptom) are that is the most truthful in the subject, but this subjective truth is not given directly, it cannot be seen directly. To be heard, the work of associations and finding of the word by the subject is necessary, creation of the story is necessary, it is necessary that it creates its own story. This work on investment with the word, creation of the story is transformation of some fact. The said fact is a remembrance picture, the same as the photo. These are raw materials, pure real thing which function is similar to the traumatic event. To become the subject's truth, passing through the word is necessary which creates the story about the event and changes thus its status, transforming into the story which we remember, into the subjective and individualized story. This fundamental difference between the remembrance - the picture being in the blank visual register, and memory - the story being in the register of the word, is the center of Hanna Arendt's works (Arendt Hannah, 1989) devoted to a culture illness.

Inaccessibility of the final reliability of the contents of own childhood forces to an incomplete effort of its thematization where the questioning subject carries out the hermeneutical interpretation work thereby establishing itself as the author of own story. In this sense establishment of some memory of childhood is the intensification, an act of the subjectification. Creating childhood memories man embodies by himself the activity asking, the intensified ability to have yourself as remembering man, believing himself as existing in this work. The childhood as the event of personal story is understood as a value, the sense made by the whole set of the personal organization, but not as autonomous, invariable, once stated state or the event.

\section{Conclusion}

In this work we tried to trace the way how the modern philosophical ideas transform an idea of the subject and the ways of subjectification. The psychoanalytic project of the subject, with its emphasis on speech, incompleteness and plurality was the basis in reflections. The main thesis of our research says that childhood in personal story does not exist as some natural, invariable fact to become a part of personal story, childhood must be called into question, articulated by means of the word in order to be appropriated. As the basis of the expansion of childhood event saturation was not a factual variety of the last experience, but the reflexive saturation, the volume and depth of the sincere experience. The thesis about the paramount importance of childhood in view of special susceptibility of a child was added with the assumption that an individual is always connected by his childhood not because this dictate is predetermined by its chronological precedence (from the point of view of classical determinism) to the other stages, and in view of habitation of other spaces of the outside world and expansion of the inner world which movements are described by the special logic of deepening, 
rediscovering and determining the senses of childhood episodes in a new way or anew. In this sense, the image of childhood is multiple, it is another depending on a character of the current peripeteia of the subject.

\section{References}

Gryakalov, A.A. (2004), The letter and event: esthetic topography of the present. SPb.

Figdor, G. (2008), Psychoanalytic pedagogics. M.: Publishing house of the Institute of Psychotherapy.

Freud, S. (2011), Psychopathology of ordinary life / Trans. Into Germ. O. Medem. SPb.: Alphabet, Azbuka-atikus.

Foucault, M. (2010) Mental illness and personality. SPb.: ITs "Humanitarian Academy". pp. 320.

Epstein, M.N. (2003) Paternity: metaphysical diary. SPb: Aleteya. pp. 248.

Arendt, Hannah (1989), La crise de la culture, trad. Fr. P. Lévy, Paris, Gallimard.

Child Analysis ... (1978) Child Analisis and Therapy/Ed. J. Glenn. New York; London.

Francoise, Dolto (1985). La Cause des enfants, éd. Robert Laffont, Paris.

Freud, S. (1957), Analysis of a phobia in a five-year-old boy//Freud S. Standard Edition. Vol. 10. London.

Klein, M. (1975), Notes on Some Schizoid Mechanisms/The Writings of Melanie Klein. Vol. 3. London.

Mamychev, A.Y., Kiyashko, E.Y. \& Timofeeva, A.A. (2015) Conservative Political Transformation Projects of the Russian Government: The Main Discourses of Contemporaneity//Mediterranean Journal of Social Sciences. Vol 6, No 3 S2. pp. 367-373.

Winnicott (1971), Playing and Reality. London. 